\title{
Comparative effects of gamma and electron beam irradiation on the antioxidant potential of Portuguese chestnuts (Castanea sativa Mill.)
}

Márcio Carocho ${ }^{\mathrm{a}}$, Amilcar L. Antonio ${ }^{\mathrm{a}, \mathrm{b}, \mathrm{c}}$, Lillian Barros ${ }^{\mathrm{a}}$, Albino Bento ${ }^{\mathrm{a}}$, M. Luisa Botelho ${ }^{\mathrm{b}}$, Iwona Kaluska ${ }^{\mathrm{d}}$, Isabel C.F.R. Ferreira ${ }^{\mathrm{a},{ }^{*}}$

${ }^{a} \mathrm{CIMO} /$ Escola Superior Agrária, Instituto Politécnico de Bragança, Apartado 1172, 5301-855 Bragança, Portugal.

bIST/ITN, Instituto Tecnológico e Nuclear, Estrada Nacional 10, 2686-953 Sacavém, Portugal.

'Departamento de Física Fundamental, Universidade de Salamanca, Plaza de la Merced, 37008 Salamanca, Spain.

${ }^{\mathrm{d}}$ Centre for Radiation Research and Technology, Institute of Nuclear Chem. and Technology, Dorodna str.16, 03-195 Warsaw, Poland

* Author to whom correspondence should be addressed (e-mail: iferreira@ipb.pt telephone +351-273-303219; fax +351-273-325405). 


\begin{abstract}
Chestnuts (Castanea sativa Mill.) are widely consumed all over the world, and have been recently studied for their antioxidant potential. The present study reports the effect of e-beam and gamma radiation (doses of $0,0.5,1$ and $3 \mathrm{kGy}$ ) on the antioxidant potential of Portuguese chestnuts. Irradiation might be an alternative preservation method, since Methyl Bromide, a widely used fumigant, was banished by the European Union in 2010 due to its toxicity. The antioxidant activity was evaluated through 2,2diphenyl-1-pycrylhydrazyl (DPPH) free radical scavenging activity assay, reducing power by the Ferricyanide/Prussian blue assay, and lipid peroxidation inhibition by $\beta$ carotene/linoleate and thiobarbituric acid reactive substances (TBARS) assays. The analysis of total phenolics and flavonoids was performed by spectrophotometric assays. Irradiated samples preserved total phenolics content (but not flavonoids) and revealed higher antioxidant activity (lower $\mathrm{EC}_{50}$ values) than the control samples. The most indicated doses to maintain antioxidants content, and to increase antioxidant activity were $1 \mathrm{kGy}$ and $3 \mathrm{kGy}$ for electron beam and gamma radiation, respectively.
\end{abstract}

Keywords: E-beam, Gamma, Irradiation, Chestnuts, Antioxidants, Phenolics, Flavonoids 


\section{Introduction}

Worldwide chestnut production is estimated to be around 1.1 million tons per year, being China the biggest producer. Europe represents $12 \%$ of the world's production, being Italy and Portugal responsible for 4 and 3\% respectively. Regarding Portugal, the Trás-os-Montes region is responsible for $82 \%$ of the entire chestnut production (Fernandes et al., 2011; Ministério da Agricultura do Desenvolvimento Rural e das Pescas, 2004). The nutritional value of chestnuts produced in the Iberian Peninsula has been extensively studied by various research groups (Barreira et al., 2009; Borges et al., 2008; Pereira-Lorenzo et al., 2006). The antioxidant potential of these nuts has also been reported by Barreira et al. (2008).

Chestnut preservation is extremely important to extend the shelf life and guarantee a pest free fruit. These concerns are even greater when the main objective is exportation. The most common preservation method was fumigation with Methyl Bromide, but since 2010, the European Union banned this chemical, under the Montreal Protocol measures (UNEP, 2006). Since then, many other preservation methods have been tried, such as heat treatment and immersion in water, but they present some disadvantages, like low efficiency, development of moulds and alteration of the chemical composition (Fernandes et al., 2011; Jeremini et al., 2006; UNEP, 2006).

Recently, irradiation has been introduced as an alternative, seen as though it does not have any negative effect on the environment, it reduces the amount of weight loss during post-harvest, doesn't leave any residues on the fruits (Jeremini et al,. 2006) and there are no significant changes in the composition of irradiated chestnuts (Antonio et al., 2011; Fernandes et al., 2011). Irradiation in the EU is only allowed with gamma rays, x-rays and electron beam. The maximum limits are $10 \mathrm{kGy}$ for gamma rays, 5 
$\mathrm{MeV}$ machines for $\mathrm{x}$-rays and $10 \mathrm{MeV}$ for electron beam. Only dried aromatic herbs, spices and vegetable seasonings are allowed to be irradiated in the EU (EU, 1999).

Although many studies should still be carried out, the effect of low doses of gamma irradiation $(0.27 \pm 0.04 \mathrm{kGy}$ or $0.54 \pm 0.04 \mathrm{kGy})$ on antioxidant potential of chestnuts was already studied, being concluded that the application of gamma irradiation showed to be advantageous for antioxidant activity, independently of the dose used (Antonio et al., 2011). Nevertheless, the storage time was more significant to chestnuts antioxidant potential than the irradiation dose.

Herein, the study was developed using higher doses $(0,0.5,1$ and $3 \mathrm{kGy})$ and eliminating the storage time effect (all the samples were analyzed immediately after irradiation). Furthermore, electron beam irradiation, a less ionizing radiation, was also tested in order to compare its effects on chestnuts antioxidant potential (free radical scavenging activity, reducing power, lipid peroxidation inhibition, total phenolics and flavonoids) with gamma irradiation.

\section{Materials and methods}

\subsection{Standards and reagents}

To prepare the acid aqueous Fricke dosimeter solution the following reagents were used: ferrous ammonium sulfate(II)hexahydrate, sodium chloride and sulfuric acid, all of them purchased from Panreac S.A. (Barcelona, Spain) with purity PA (proanalysis), and water treated in a Milli-Q water purification system (Millipore, model A10, USA). 2,2-Diphenyl-1-picrylhydrazyl (DPPH) was obtained from Alfa Aesar (Ward Hill, MA, USA). The standards trolox (6-hydroxy-2,5,7,8-tetramethylchroman-2-carboxylic acid), gallic acid and (+)-catechin were purchased from Sigma (St. Louis, MO, USA). Methanol and all other chemicals were of analytical grade and obtained from common 
sources. Water was treated in a Milli-Q water purification system (TGI Pure Water Systems, USA).

\subsection{Samples}

Chestnuts (Castanea sativa Mill.) samples were obtained from Bragança, Trás-osMontes (Portugal). For each irradiation procedure, they were divided in four groups: control (non-irradiated, $0 \mathrm{kGy})$, sample 1 (0.5 kGy), sample 2 (1 kGy), and sample 3 (3 kGy) with fifteen units per group (Figure 1A). An independently control was used for each irradiation procedure (gamma and electron beam performed in Portugal and Poland, respectively), in order to guarantee the same conditions for all the samples. Previous to chestnuts irradiation, a dosimetric study was performed using a chemical solution sensitive to ionizing radiation, called Fricke dosimeter.

\subsection{Samples irradiation}

Gamma radiation. The irradiation of the samples was performed in a Co-60 experimental chamber with four sources, a total activity of $267 \mathrm{TBq}(6.35 \mathrm{kCi})$ in November 2011 (Precisa 22, Graviner Manufacturing Company Ltd, U.K.) (Figure 1B). After irradiation geometry dose rate estimation, using the Fricke dosimeter and the procedure described in the standards (ASTM, 1992), the groups for irradiation were placed in Poly(methyl methacrylate) (PMMA) box, or acrylic glass, and irradiated at ambient atmosphere and temperature $\left(15^{\circ} \mathrm{C}\right)$ (Figure 1C). During the irradiation process, 4 routine dosimeters were used for each group for the higher dose to monitor the process (Amber Perspex dosimeters, from Harwell Company, U.K.). The samples were rotated up-side down $\left(180^{\circ}\right)$ at half of the time, to increase the dose uniformity. The Amber Perspex dosimeters were read in a UV-VIS Spectrophotomer (Shimadzu 
mini UV 1240 spectrophotometer) at $603 \mathrm{~nm}$, two readings for each, to estimate the dose according to a previous calibration curve.

The estimated doses after irradiation were $0.6 \pm 0.1 \mathrm{kGy}, 1.1 \pm 0.1 \mathrm{kGy}$ and $3 \pm 0.3 \mathrm{kGy}$ for each of the mentioned groups, respectively, at a dose rate of $0.8 \pm 0.1 \mathrm{kGy} \mathrm{h}^{-1}$. For simplicity, from now on, in the tables and graphs we considered the values $0,0.5,1$ and $3 \mathrm{kGy}$, for non-irradiated and irradiated samples.

Electron beam radiation. The irradiation with electrons was performed at the INCT Institute of Nuclear Chemistry and Technology - in Warsaw, Poland, with an e-beam of $10 \mathrm{MeV}$ of energy (Figure 1D). Pulse duration $5.5 \mu$ s, pulse frequency $440 \mathrm{~Hz}$, average beam current $1.1 \mathrm{~mA}$, scan width of $68 \mathrm{~cm}$, conveyer speed in the range $20-100 \mathrm{~cm} / \mathrm{min}$, scan frequency $5 \mathrm{~Hz}$. The absorbed dose was $0.53,0.83$ and $2.91 \mathrm{kGy}$, with an uncertainty of $20 \%$ for two first doses and $15 \%$ for the last dose. To estimate the dose, Amber Perspex and Gammachrome YR dosimeters (from Harwell Company, U.K.) and a Graphite Calorimeter were used, depending on the dose level. The procedure to read the Amber and Gammachrome YR dosimeters was the one described above. The electrical resistance was read for the calorimeter dosimeter and converted in dose according to a previous calibrated curve.

\subsection{Antioxidant activity evaluation}

Extraction procedure. After irradiation, all the samples were lyophilized (FreeZone 4.5 model 7750031, Labconco, Kansas, USA), reduced to a fine dried powder (20 mesh) and mixed to obtain homogenate samples. The lyophilized powder $(1 \mathrm{~g})$ was stirred with methanol $(30 \mathrm{~mL})$ at $25^{\circ} \mathrm{C}$ at $150 \mathrm{rpm}$ for $1 \mathrm{~h}$ and filtered through Whatman No. 4 paper. The residue was then extracted with an additional portion of methanol. The 
combined methanolic extracts were evaporated under reduced pressure (rotary evaporator Büchi R-210; Flawil, Switzerland), re-dissolved in methanol at $10 \mathrm{mg} / \mathrm{mL}$ (stock solution), and stored at $4{ }^{\circ} \mathrm{C}$ for further use. Successive dilutions were made from the stock solution and submitted to in vitro assays already described by the authors (Antonio et al., 2011) to evaluate the antioxidant activity of the samples. The sample concentrations providing $50 \%$ of antioxidant activity or 0.5 of absorbance $\left(\mathrm{EC}_{50}\right)$ were calculated from the graphs of antioxidant activity percentages (DPPH, $\beta$ carotene/linoleate and TBARS assays) or absorbance at $690 \mathrm{~nm}$ (reducing power assay) against sample concentrations. Trolox was used as standard.

Total phenolics. Phenolics were determined by the Folin-Ciocalteu assay, measuring the absorbance at $765 \mathrm{~nm}$. Gallic acid was used to obtain the standard curve $\left(9.4 \times 10^{-3}\right.$ $1.5 \times 10^{-1} \mathrm{mg} / \mathrm{mL}$ ), and the results were expressed as $\mathrm{mg}$ of gallic acid equivalents (GAE) per g of extract.

Total flavonoids. Flavonoids were determined by the $\mathrm{AlCl}_{3}$ assay, measuring the absorbance at $510 \mathrm{~nm} .(+)$-Catechin was used to calculate the standard curve $\left(4.5 \times 10^{-3}\right.$ $\left.2.9 \times 10^{-1} \mathrm{mg} / \mathrm{mL}\right)$ and the results were expressed as $\mathrm{mg}$ of $(+)$-catechin equivalents $(\mathrm{CE})$ per $g$ of extract.

DPPH radical scavenging activity. This methodology was performed by using an ELX800 microplate reader (Bio-Tek Instruments, Inc; Winooski, USA), and calculated as a percentage of DPPH discolouration using the formula: $\left[\left(\mathrm{A}_{\mathrm{DPPH}}-\mathrm{A}_{\mathrm{S}}\right) / \mathrm{A}_{\mathrm{DPPH}}\right] \times 100$, where $A_{S}$ is the absorbance of the solution containing the sample at $515 \mathrm{~nm}$, and $A_{D P P H}$ is the absorbance of the DPPH solution. 
Reducing power. This methodology evaluated the capacity to convert $\mathrm{Fe}^{3+}$ into $\mathrm{Fe}^{2+}$, measuring the absorbance at $690 \mathrm{~nm}$ in the microplate reader mentioned above.

Inhibition of $\beta$-carotene bleaching. This capacity was evaluated though the $\beta$ carotene/linoleate assay; the neutralization of linoleate free radicals avoids $\beta$-carotene bleaching, which was measured by the formula: $\beta$-carotene absorbance after $2 \mathrm{~h}$ of assay/initial absorbance) $\times 100$.

TBARS assay. Lipid peroxidation inhibition in porcine (Sus scrofa) brain homogenates was evaluated by the decreasing in thiobarbituric acid reactive substances (TBARS); the colour intensity of the malondialdehyde-thiobarbituric acid (MDA-TBA) was measured by its absorbance at $532 \mathrm{~nm}$; the inhibition ratio (\%) was calculated using the following formula: $[(\mathrm{A}-\mathrm{B}) / \mathrm{A}] \times 100 \%$, where $\mathrm{A}$ and $\mathrm{B}$ were the absorbance of the control and the sample solution, respectively.

\subsection{Statistical analysis}

Three replicates of each sample were used and all the assays were carried out in triplicate. The results are expressed as mean values and standard deviation (SD). The results were analyzed using one-way analysis of variance (ANOVA) followed by Tukey's HSD Test with $\alpha=0.05$. This analysis was carried out using SPSS v. 18.0 program.

\section{Results and discussion}


The antioxidant potential was analyzed through total phenolics and flavonoids content, as well as DDPH scavenging activity, reducing power, $\beta$-carotene bleaching inhibition and inhibition of lipid peroxidation using thiobarbituric acid reactive substances (TBARS). The results obtained for the samples submitted to electron beam and gamma radiation are presented in Table $\mathbf{1}$ and $\mathbf{2}$, respectively.

Regarding electron beam radiation, it is clear that the best irradiation dose was $1 \mathrm{kGy}$, where the samples revealed the highest phenolics content ( $8.16 \mathrm{mg}$ GAE/g extract) and the highest antioxidant activity (lowest $\mathrm{EC}_{50}$ values, 1.66 to $2.81 \mathrm{mg} / \mathrm{mL}$ ) in general. Flavonoids were affected by electron beam radiation, since the highest level was observed in the control sample (2.34 $\mathrm{mg} \mathrm{CE} / \mathrm{g}$ extract). Therefore, electron beam irradiated samples preserved phenolics since these samples present higher concentrations of the mentioned compounds than the control sample (non-irradiated) (Table 1). Moreover, all the irradiated samples $(0.5,1$ and $3 \mathrm{kGy})$ revealed higher antioxidant activity (lower $\mathrm{EC}_{50}$ values) than the control sample in all the assayed methods.

Concerning gamma radiation, it is clear that the best dose was $3 \mathrm{kGy}$; those samples proved to have the highest content in phenolics (5.55 $\mathrm{mg}$ GAE/g extract; without statistical significant differences in relation to samples irradiated with $1 \mathrm{kGy}$ ) and the lowest $\mathrm{EC}_{50}$ values for DPPH scavenging activity, $\beta$-carotene bleaching and TBARS inhibition (the last one also without statistical significant differences in relation to samples irradiated with $1 \mathrm{kGy})$. Otherwise, control samples gave the highest flavonoids content (1.21 mg CE/g extract), and the highest reducing power (lowest $\mathrm{EC}_{50}$ value; $2.81 \mathrm{mg} / \mathrm{mL}$ ). The obtained results are in agreement with a previous study in chestnuts irradiated with low doses of gamma radiation $(\leq 0.5 \mathrm{kGy})$, where it was concluded that the application of gamma irradiation showed to be advantageous for antioxidant 
activity, independently of the dose used (Antonio et al., 2011). Furthermore, the control samples (especially in electron beam irradiation) revealed very close $\mathrm{EC}_{50}$ values (DDPH scavenging activity, reducing power and $\beta$-carotene bleaching inhibition) to a previous study in non-irradiated chestnuts (Barreira et al., 2008).

Figure 2 represents individually the results obtained in each antioxidant activity assay for the best dose of each radiation type ( 1 and $3 \mathrm{kGy}$ for electron beam and gamma radiation, respectively), in comparison with control samples. Irradiated samples showed higher DPPH scavenging activity, reducing power and $\beta$-carotene bleaching inhibition than control samples. Chestnuts irradiated with gamma irradiation at $3 \mathrm{kGy}$ revealed the highest DPPH scavenging activity (Figure 2A), while chestnuts irradiated with electron beam radiation at $1 \mathrm{kGy}$ revealed the highest reducing power (Figure $\mathbf{2 B}$ ), $\beta$-carotene bleaching inhibition and TBARS inhibition (Figure 2C).

The control samples of both radiations types (gamma and electron beam) correlated quite well with flavonoids, displaying a $\mathrm{R}^{2}$ of $0.9430,0.7909$ and 0.7426 for DPPH scavenging activity, reducing power and TBARS inhibition, respectively. These results are once more in agreement with the results published by Barreira et al., (2008), proving that flavonoids are a group of polyphenols that contribute in a great manner for chestnuts antioxidant activity. In fact, these phenolic compounds are widely found in chestnuts (Dinis et al., 2012) and, in some cases represent an average of $0.88 \%$ of their dry weight (Kapusta et al., 2007). Flavonoids, are proven to be the major contributor to the scavenging of reactive oxygen species and to have a potent cell-protective effect (Masaki et al., 1995). Nevertheless, the correlations between antioxidant activity of irradiated samples and flavonoids decreased drastically $\left(\mathrm{R}^{2}<3.00\right)$ revealing that these compounds may be sensitive to both electron beam and gamma radiation (indicated by the decrease in flavonoids content observed in irradiated samples). Despite the decrease 
in flavonoids (a class of phenolic compounds), total phenolics increased which could be responsible for the increasing in antioxidant potential of irradiated samples. Therefore, it can be concluded that other phenolic compounds but not flavonoids contribute more for antioxidant activity.

Overall, irradiated samples preserved total phenolics content (certainly other phenolic compounds rather than flavonoids) and revealed higher antioxidant activity (lower $\mathrm{EC}_{50}$ values) than the control samples. The most indicated doses to maintain antioxidants content, and to increase antioxidant activity were $1 \mathrm{kGy}$ and $3 \mathrm{kGy}$ for electron beam and gamma radiation, respectively. Future studies should be performed in order to evaluate the effects of irradiation in individual phenolic compounds, using chromatographic techniques.

The authors declare that they not have any conflict of interest.

\section{Acknowledgements}

The authors thank ON.2/QREN/EU Project no.13198/2010 for financial support of this work, to Fundação para a Ciência e a Tecnologia (FCT, Portugal) and COMPETE/QREN/EU for financial support to CIMO (strategic project PEstOE/AGR/UI0690/2011). A. Antonio and L. Barros also thank to FCT, POPH-QREN and FSE for their grants (SFRH/PROTEC/67398/2010 and SFRH/BPD/4609/2008, respectively). Prof. A. Chmielewski, General Director of the Institute of Nuclear Chemistry and Technology, Warsaw, Poland, for allowing e-beam irradiations. 


\section{References}

Antonio, A.L., Fernandes, Â., Barreira, J.C.M., Bento, A., Botelho, M.L., Ferreira, I.C.F.R. 2011. Influence of gamma irradiation in the antioxidant potential of chestnuts (Castanea sativa Mill.) fruits and skins. Food and Chem. Toxicol. 49, 1918-1923.

ASTM, American Society for Testing and Materials, 1992. Practice for Using the Fricke Reference Standard Dosimetry System. ASTM E1026, Annual Book of ASTM Standards, 12.02, Philadelphia, PA.

Barreira, J.C.M., Ferreira, I.C.F.R., Oliveira, M.B.P.P., Pereira, J.A. 2008. Antioxidant activities of the extracts from chestnut flower, leaf, skins and fruit. Food Chem. 107, 1106-1113.

Barreira, J.C.M., Casal S., Ferreira, I.C.F.R., Oliveira, M.B.P.P., Pereira, J.A. 2009. Nutritional, Fatty Acid and Triacylglycerol Profiles of Castanea sativa Mill. Cultivars: A Compositional and Chemometric Approach. J. Agri. Food Chem. 57, 2836-2842.

Barros, L., Carvalho, A.M.., Ferreira, I.C.F.R. 2010. Leaves, flowers, immature fruits and leafy flowered stems of Malva sylvestris: A comparative study of the nutraceutical potential and composition. Food Chem. Toxicol. 48, 1466-1472.

Borges, O., Gonçalves, B., Carvalho, J.L.S., Correia, P., Silva, A.P. 2008. Nutritional quality of chestnut (Castanea sativa Mill.) cultivars from Portugal. Food Chem. 976-984.

Dinis, L., Oliveira, M.M., Alemida, J., Costa, R., Gomes-Laranjo, J., Peixoto, F. 2012. Antioxidant activities of chestnut nut of Castanea sativa Mill. (cultivar 'Judia') as function of origin ecosystem. Food Chem. 132, 1-8. 
EU Directive 1999/2/EC of the European parliament and of the council of 22 February 1999.

Fernandes, Â., António, A., Barros, L., Barreira, J.C.M., Bento, A., Botelho, M.L., Ferreira, I.C.F.R. 2011. Low dose $\gamma$-irradiation as a suitable solution for chestnut (Castanea sativa Miller) conservation: effects on sugars, fatty acids and tocopherols. J. Agric. Food Chem. 59, 10028-10033.

Fernandes, Â., Barreira, J.C.M., António, A.L., Bento, A., Botelho, M.L., Ferreira, I.C.F.R. 2011. Assessing the effects of gamma irradiation and storage time in energetic value and in major individual nutrients of chestnuts. Food Chem. Toxicol. 49, 2429-2432.

Jeremini, M., Conedera, M., Sieber, T.N., Sassella, A., Schärer, H., Jelmini, G., Höhn, E. 2006. Influence of fruit treatments on perishability during cold storage of sweet chestnuts. J. Sci. Food Agric. 86, 877-885.

Kapusta, I., Janda, B., Szajwaj, B., Stochmal, A., Piacente, S., Pizza, C., Francheschi, F., Franz, C., Oleszek, W. 2007. Flavonoids in horse chestnut (Aesculus hippocastanum) seeds and powdered waste water byproducts. J. Agric. Food Chem. 55, 8485-8490.

Masaki, H., Sakaki, S., Atsumi, T., Sakuari, H. 1995. Active-oxygen scavenging activity of plant extracts. Biol. Pharma. Bull. 18,162-166.

Ministério da Agricultura do Desenvolvimento Rural e das Pescas. http://portal.minagricultura.pt/portal/page/portal/MADRP/PT; $\quad$ http://www.gppaa.minagricultura.pt/pbl/diagnosticos/subfileiras/Castanha.pdf; http://www.gppaa.minagricultura.pt/ (Accessed January 2011. Data from 2004). 
Pereira-Lorenzo, S., Ramos-Cabrer, A.M., Díaz-Hernández, M.B., Ciordia-Ara, M., Ríos-Mesa, D. 2006. Chemical composition of chestnut cultivars from Spain. Sci. Hortic. 107, 306-314.

UNEP, Montreal Protocol on substances that deplete the ozone layer, 2006. Report of the Methyl Bromide Technical Options Committee, 205-206, 310-313. 
Table 1. Phenolics (mg GAE/g extract), flavonoids (mg CE/g extract) and antioxidant activity $\left(\mathrm{EC}_{50}\right.$ values, $\left.\mathrm{mg} / \mathrm{mL}\right)$ of chestnuts submitted to electron beam irradiation. Mean \pm SD ( $=9)$.

\begin{tabular}{lllll}
\hline & Control & $0.5 \mathrm{kGy}$ & $1 \mathrm{kGy}$ & $3 \mathrm{kGy}$ \\
\hline Phenolics & $3.61 \pm 0.57^{\mathrm{d}}$ & $4.06 \pm 0.93^{\mathrm{c}}$ & $8.16 \pm 0.34^{\mathrm{a}}$ & $5.60 \pm 0.50^{\mathrm{b}}$ \\
Flavonoids & $2.34 \pm 0.25^{\mathrm{a}}$ & $0.40 \pm 0.05^{\mathrm{b}}$ & $0.31 \pm 0.06^{\mathrm{c}}$ & $0.24 \pm 0.06^{\mathrm{c}}$ \\
DPPH scavenging activity & $25.12 \pm 1.11^{\mathrm{a}}$ & $23.27 \pm 2.61^{\mathrm{b}}$ & $15.93 \pm 0.71^{\mathrm{c}}$ & $13.81 \pm 1.67^{\mathrm{d}}$ \\
Reducing power & $7.05 \pm 0.96^{\mathrm{a}}$ & $6.31 \pm 0.59^{\mathrm{b}}$ & $2.81 \pm 0.10^{\mathrm{d}}$ & $5.36 \pm 0.27^{\mathrm{c}}$ \\
B-carotene bleaching inhibition & $6.00 \pm 0.53^{\mathrm{b}}$ & $2.54 \pm 0.37^{\mathrm{c}}$ & $1.94 \pm 0.20^{\mathrm{d}}$ & $6.95 \pm 1.09^{\mathrm{a}}$ \\
& $10.63 \pm 1.72^{\mathrm{a}}$ & $4.06 \pm 1.28^{\mathrm{c}}$ & $1.66 \pm 0.41^{\mathrm{d}}$ & $7.82 \pm 2.77^{\mathrm{b}}$ \\
\hline TBARS inhibition & & & & \\
\hline
\end{tabular}

In each row, different letters mean significant differences between doses $(p<0.05)$.

Concerning the antioxidant activity assays, the results are presented in $\mathrm{EC}_{50}$ values, what means that higher values correspond to lower reducing power or antioxidant potential. $\mathrm{EC}_{50}$ : Extract concentration corresponding to $50 \%$ of antioxidant activity or 0.5 of absorbance for the reducing power assay. 
Table 2. Phenolics (mg GAE/g extract), flavonoids (mg CE/g extract) and antioxidant activity $\left(\mathrm{EC}_{50}\right.$ values, $\mathrm{mg} / \mathrm{mL}$ ) of chestnuts submitted to gamma irradiation. Mean $\pm \mathrm{SD}$ $(n=9)$.

\begin{tabular}{lllll}
\hline & Control & $0.5 \mathrm{kGy}$ & $1 \mathrm{kGy}$ & $3 \mathrm{kGy}$ \\
\hline Phenolics & $3.63 \pm 0.01^{\mathrm{c}}$ & $4.26 \pm 0.44^{\mathrm{b}}$ & $5.07 \pm 0.42^{\mathrm{a}}$ & $5.55 \pm 1.21^{\mathrm{a}}$ \\
Flavonoids & $1.21 \pm 0.00^{\mathrm{a}}$ & $1.15 \pm 0.11^{\mathrm{a}}$ & $0.42 \pm 0.04^{\mathrm{b}}$ & $0.55 \pm 0.05^{\mathrm{b}}$ \\
DPPH scavenging activity & $38.72 \pm 0.85^{\mathrm{b}}$ & $45.48 \pm 2.43^{\mathrm{a}}$ & $15.05 \pm 0.94^{\mathrm{c}}$ & $11.30 \pm 0.92^{\mathrm{d}}$ \\
Reducing power & $2.81 \pm 0.03^{\mathrm{c}}$ & $5.30 \pm 0.62^{\mathrm{a}}$ & $5.45 \pm 0.73^{\mathrm{a}}$ & $4.05 \pm 0.69^{\mathrm{b}}$ \\
B-carotene bleaching inhibition & $6.38 \pm 0.66^{\mathrm{b}}$ & $9.23 \pm 1.31^{\mathrm{a}}$ & $3.60 \pm 0.54^{\mathrm{c}}$ & $2.51 \pm 0.37^{\mathrm{d}}$ \\
& $5.21 \pm 0.36^{\mathrm{b}}$ & $10.22 \pm 1.29^{\mathrm{a}}$ & $1.09 \pm 0.42^{\mathrm{c}}$ & $0.86 \pm 0.21^{\mathrm{c}}$ \\
TBARS inhibition & & & & \\
\hline
\end{tabular}



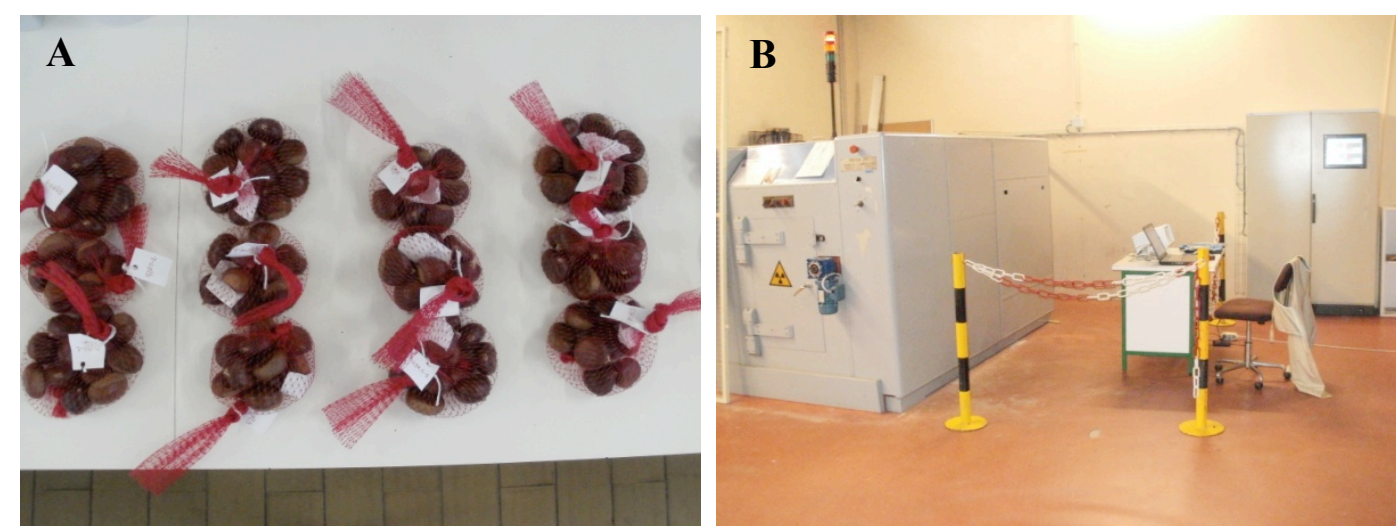

C
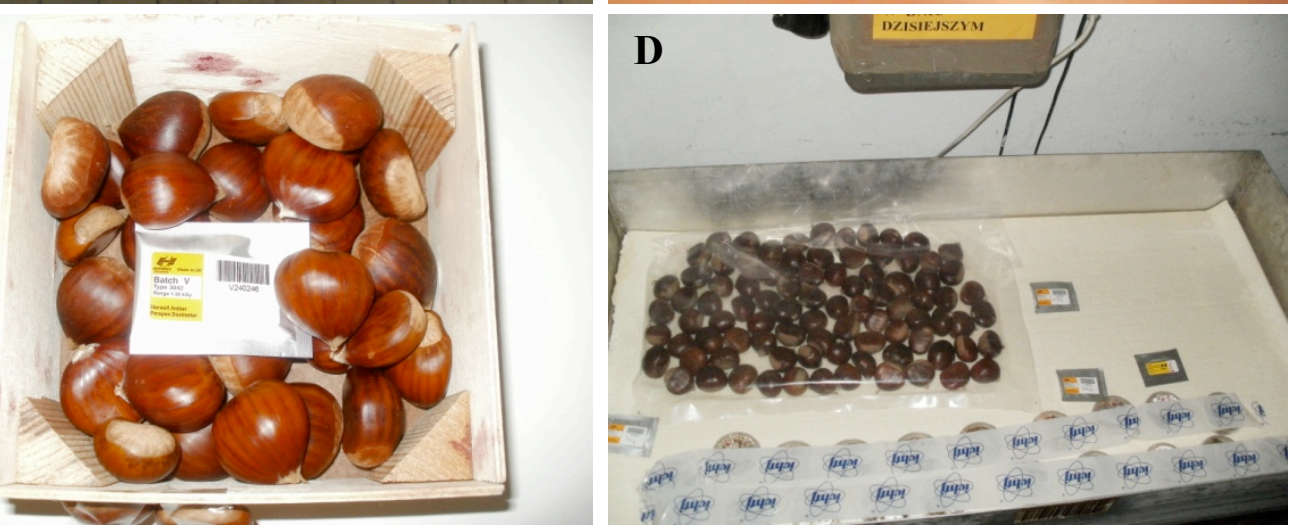

Figure 1. A. Chestnuts after electron beam irradiation, from left to right: Control (0 kGy), 0.5 kGy, 1 kGy and 3 kGy. B. Gamma irradiation chamber. C. Chestnuts with corresponding dosimeter inside a Poly(methyl methacrylate) box before gamma irradiation. D. Chestnuts with corresponding dosimeters before electron beam irradiation. 


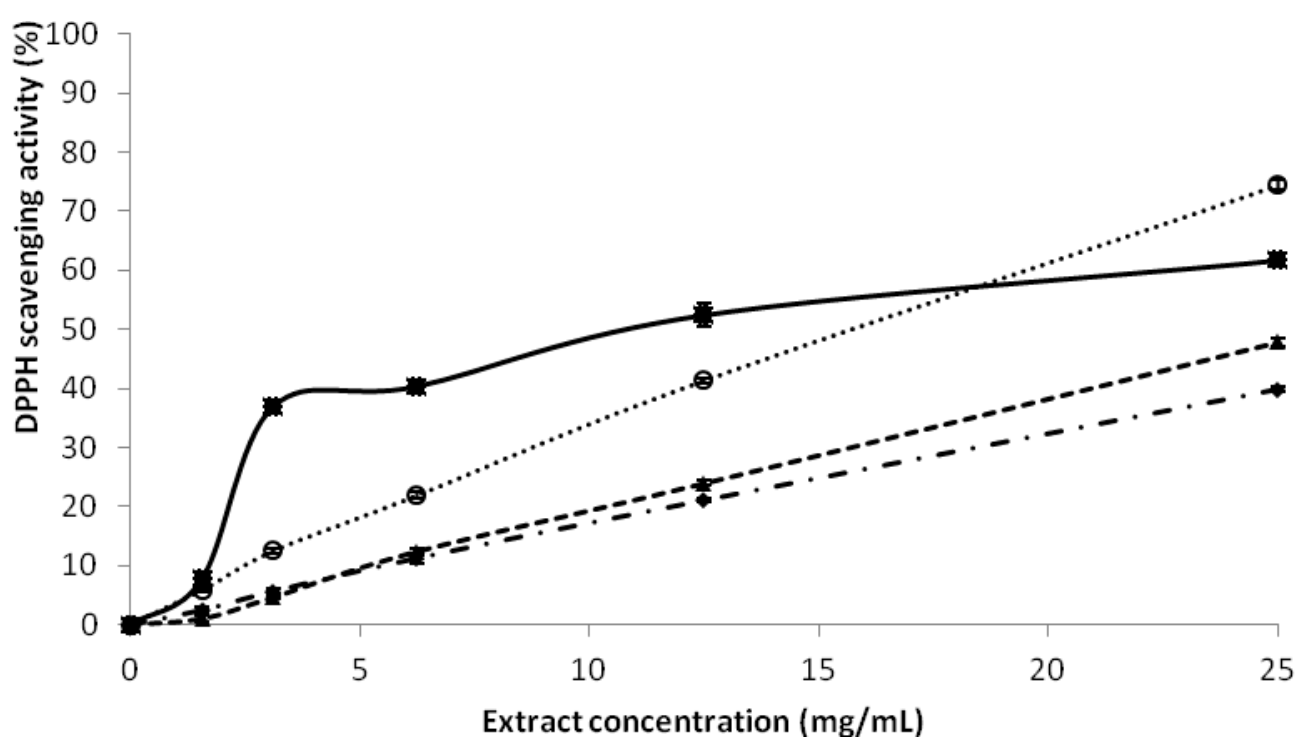

A

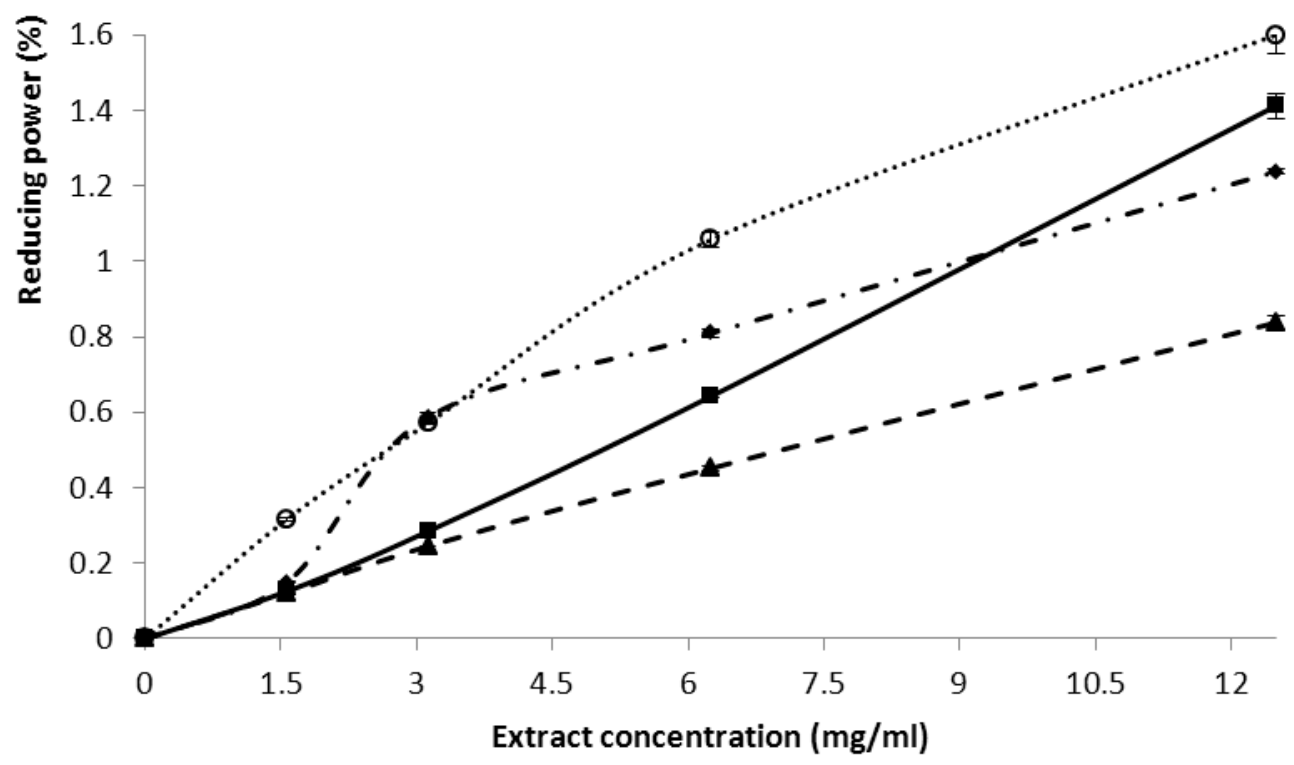

B 


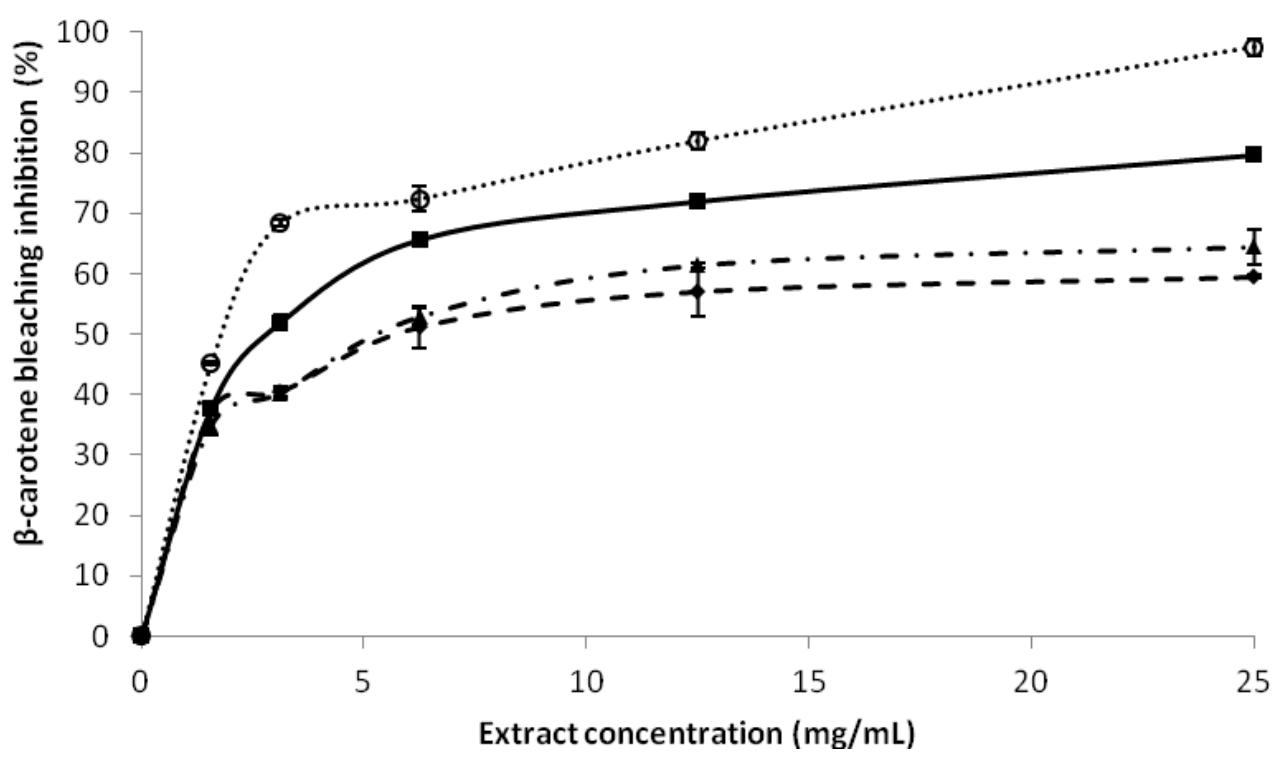

C

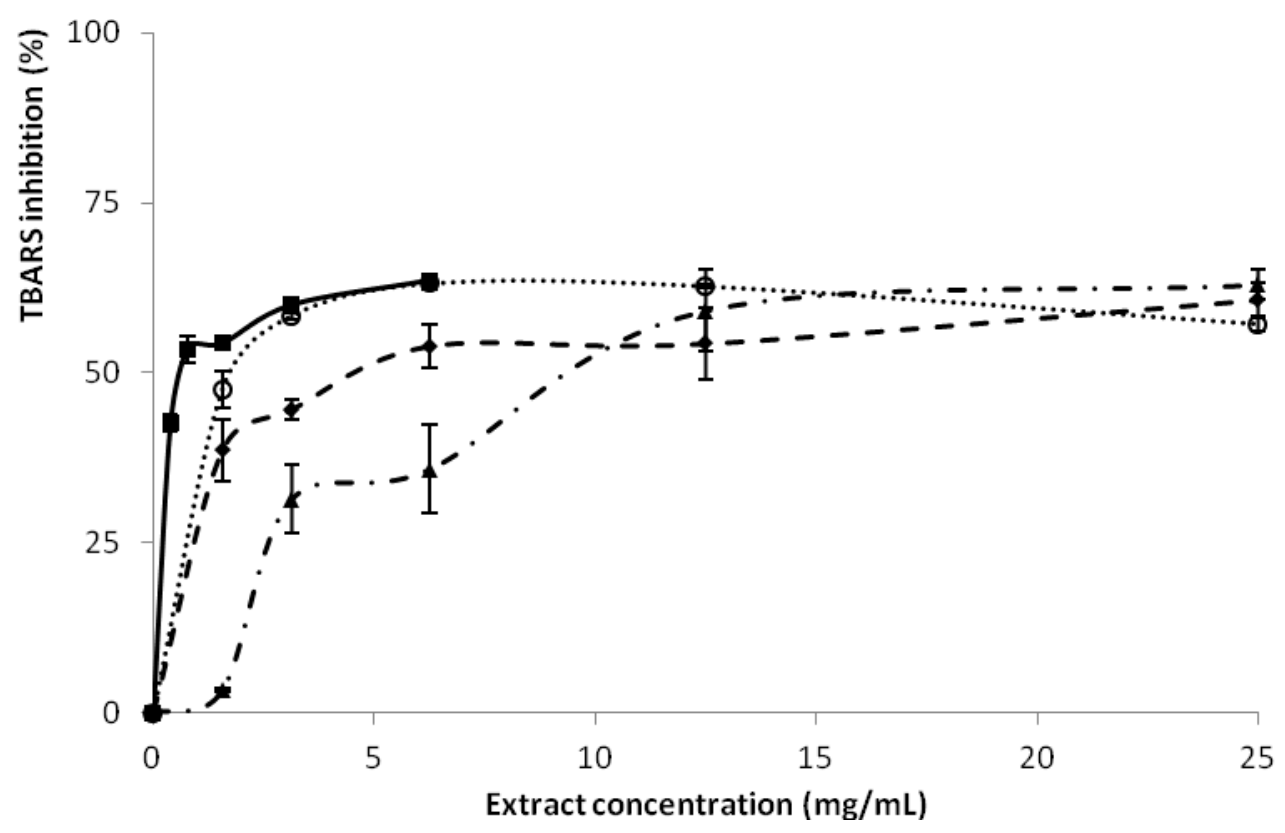

D

Figure 2. DPPH scavenging activity (A), reducing power (B), $\beta$-carotene bleaching inhibition (C) and TBARS inhibition (D) of chestnut samples (Mean $\pm \mathrm{SE} ; \mathrm{n}=9$ ): submitted to electron beam- control ( - \pm- ) and $1 \mathrm{kGy}(\quad \cdots \cdot \odot \cdots)$; submitted to gamma radiation- control ( $\bullet-)$ ) and $3 \mathrm{kGy}(\longrightarrow-)$ ). 